\title{
WELTMANN COAGULATION REACTION IN RHEUMATOID ARTHRITIS
}

\author{
BY \\ OSWALDO LUCCHESI, MARCELLO LUCCHESI \\ and \\ SILVIO BAILONIE* \\ From the Brazilian League against Rheumatism and the Pan American League for the Study and Control of the Rheumatic Diseases
}

Oskar Weltmann (1930) showed that human blood serum diluted in distilled water in the proportion of $1: 50$ does not become turbid at the temperature of boiling water. In the Weltmann reaction the degree of flocculation depends on the addition of electrolytes through heat. Thus, varying with the pathological process, the diluted serum needs different quantities of bivalent electrolytes for the hot flocculation to take place. Bonilla and Lagrotta explained that if, instead of using distilled water, we proceed to the dilution of serum in ordinary water or in normal saline, we will succeed in promoting flocculation in normal serum, provided that adequate concentrations of an electrolyte are present-as, for example, calcium, barium, or magnesium chloride, ammonium sulphate, etc. Weltmann, taking this fact as a basis, developed a technique for the determination of the "electrolytic threshold" of the sera and the alterations which it may suffer in various pathological conditions. In order to produce a flocculation, it is, therefore, necessary to add larger calcium chloride concentrations to the serum of exudative processes than to normal serum. In the presence of hepatic cirrhosis and chronic proliferative diseases, a smaller amount of electrolyte is necessary. The mechanical working of this reaction seems to depend not on a close relationship with the total proteins of the serum, nor on the serum albumin-globulin ratio, but on the qualitative modifications of the serum proteins caused by the tissue alterations originating from exudative or fibrotic processes.

There are in the literature only two papers on the employment of the Weltmann test in rheumatoid arthritis. They are those of Milles and Salt, and of Kling, both published in 1941. Milles and Salt, in 150 cases of rheumatoid arthritis, investigated the erythrocyte sedimentation rate, the formol-gel test, and the Weltmann and Takata-Ara reactions, and concluded that the sedimentation rate and the Weltmann reaction are extremely sensitive indices of the severity of the complaint, although the results of the two tests are not always parallel. In some patients with a serious form of rheumatoid arthritis the shift of the flocculation band toward the left

* Read before the First Paulista Congress of Rheumatology, and the Second Medical Congress of São Paulo, Brazil, on March 2, 1945. was moderate. Kling, after investigating 98 cases of rheumatoid arthritis, also concluded that the Weltmann reaction does not possess the same sensitiveness as the sedimentation rate, which appeared to him to be a more exact index of the clinical progress of the disease, and of the therapeutic results. In his cases a marked narrowing of the flocculation band occurred only in $53 \%$, while the sedimentation rate showed an increase in $82 \%$.

It appears that the meaning of the serum flocculation band in rheumatic diseases has not yet been investigated sufficiently. Severe rheumatoid arthritis seems to be characterized by a moderate shift to the left of the serum flocculation band. This shift to the left should be much more marked in the acute stage of rheumatic fever. A shift to the right has also been recorded in a few cases of rheumatoid arthritis, and when this is so the prognosis would appear to be good.

\section{Weltmann Coagulation Reaction Technique}

Take ten test-tubes, each containing $5 \mathrm{c} . \mathrm{cm}$. of differing calcium chloride concentrations, and add $1 / 10 \mathrm{c.cm}$. of non-haemolyzed human serum. These calcium chloride concentrations are obtained from a $10 \%$ titred solution divided into ten titre-decreasing solutions, running from 1 to 10 and starting with the more concentrated, in the order shown in Table 1.

TABLE 1

\begin{tabular}{c|c|c|c|c|c|c|c|c|c|c}
\hline Tubes & 1 & 2 & 3 & 4 & 5 & 6 & 7 & 8 & 9 & 10 \\
\hline $\begin{array}{c}0 / 00 \mathrm{Ca} \mathrm{Cl}_{2} \\
\text { concentration }\end{array}$ & $1 \cdot 0$ & 0.9 & $0 \cdot 8$ & $0 \cdot 7$ & $0 \cdot 6$ & $0 \cdot 5$ & $0 \cdot 4$ & $0 \cdot 3$ & $0 \cdot 2$ & $0 \cdot 1$ \\
\hline $\begin{array}{c}\text { Interpretation } \\
\text { findings. }\end{array}$ & $\begin{array}{l}\text { Narrowed floc- } \\
\text { culation band, } \\
\text { or shift to the } \\
\text { left. } \\
\text { Exudative pro- } \\
\text { cesses. }\end{array}$ & $\begin{array}{c}\text { No r mal } \\
\text { floccula- } \\
\text { t i o n } \\
\text { band. }\end{array}$ & $\begin{array}{c}\text { Enlarged floccu- } \\
\text { lation band, or } \\
\text { shift to the right. }\end{array}$ \\
\hline
\end{tabular}

The tubes are left in boiling water for 15 minutes, after which time the reading is proceeded with. The "flocculation band" is the coagulation which occurs in some tubes. The flocculation occurs more readily in tubes containing high electrolytic concentrationsnormally tubes 6 or 7 . When the flocculation takes place below tube 6 , we say that there is a shift to the left, 
or a narrowing of the flocculation band; and when it takes place above tube 7 , a shift to the right, or an enlargement of the flocculation band. In normal subjects the flocculation band occurs in tubes 6 and 7 . In the exudative processes there is a shift to the left (a narrowing of the band), while in the proliferative, chronic processes the shift is to the right (an enlargement of the band).

\section{Clinical Material}

Our investigation was on patients from our private clinic, and represented a group of 85 cases divided as follows: (1) 66 cases of rheumatoid arthritis, with 180 Weltmann reactions; (2) 4 cases of rheumatic fever, and 4 Weltmann reactions; and (3) 15 normal subjects with 16 Weltmann reactions. Among the patients with rheumatoid arthritis, 34 were women and 32 men. The youngest patient was 16 years old, and the oldest was 73 . The mean age was 42. The duration of the arthritis varied from 4 days in the most recent case to 50 years in the oldest. The mean duration was 6 years (see Table 2).

TABLE 2.

CASES OF RHEUMATOID ARTHRITIS

\begin{tabular}{|c|c|c|c|c|c|}
\hline \multirow{2}{*}{ Age group } & \multirow{2}{*}{$\begin{array}{l}\text { No. in } \\
\text { group }\end{array}$} & \multicolumn{2}{|c|}{ Sex } & \multirow{2}{*}{$\begin{array}{l}\text { Age at onset } \\
\text { of arthritis- } \\
\text { No. of cases }\end{array}$} & \multirow{2}{*}{$\begin{array}{l}\text { Stage of arthritis- } \\
\text { No. of cases }\end{array}$} \\
\hline & & $\mathbf{F}$ & $\mathbf{M}$ & & \\
\hline $\begin{array}{c}0-9 \\
10-19 \\
20-29 \\
30-39 \\
40-49 \\
50-59 \\
60-69 \\
70-79\end{array}$ & $\begin{array}{r}0 \\
2 \\
13 \\
11 \\
24 \\
7 \\
6 \\
3\end{array}$ & $\begin{array}{r}7 \\
6 \\
13 \\
5 \\
2 \\
1\end{array}$ & $\begin{array}{r}2 \\
6 \\
5 \\
11 \\
2 \\
4 \\
2\end{array}$ & $\begin{array}{r}1 \\
5 \\
19 \\
13 \\
17 \\
5 \\
3 \\
3\end{array}$ & $\begin{array}{ccc}\text { Early, moderately ad- } & \text { anced, or advanced } \\
\text { vanced } & \\
\text { arthritis } & . . & 55 \\
\text { Terminal stage } & . & 11\end{array}$ \\
\hline
\end{tabular}

We tested the Weltmann reaction altogether 200 times in the 85 cases. We were able to follow up for a period of from 2 to 6 months the progress of 40 out of the 66 patients with rheumatoid arthritis; the remaining 26 had their reactions recorded at the time of consultation only.

\section{Results}

The two following tables show the results obtained compared with the sedimentation rate (Westergren).

In Table 3 are included all the results obtained by means of the Weltmann reactions and sedimentation rates-repeated, in some cases, during the progress of the arthritis.

We considered the limit-values to be as follows:

Normal coagulation band

Engiarged coagulation band Slightly narrowed coagulation band.

Markedly narrowed coagulation band.

Normal values of sedimentation rate.

Slightly increased sedimentation rate.

Increased sedimentation rate.
Flocculation in tubes 6 . and 7.

\section{, above tube 7}

in tube 5 .

, below tube 5 .

Between 1 and $10 \mathrm{~mm}$. in the $1 \mathrm{st}$ hour.

11 and $30 \mathrm{~mm}$. in the 1st hour.

Above $30 \mathrm{~mm}$. in the $1 \mathrm{st}$. hour.
TABLE 3.

Total Results of 180 Weltmann Tests and SediMENTATION RATE IN 66 CASES OF RHEUMATOID ARTHRitis IN THeir Different Stages.

\begin{tabular}{|c|c|c|c|c|}
\hline $\begin{array}{l}\text { Weltmann } \\
\text { Reaction } \\
\left(\mathrm{Ca} \mathrm{Cl}_{2}\right)\end{array}$ & Tube & Percentage & $\begin{array}{l}\text { Sedimenta- } \\
\text { tion Rate }\end{array}$ & Percentage \\
\hline $\begin{array}{l}0.1 \\
0.2 \\
0.3 \\
0.4 \\
0.5 \\
0.6 \\
0.7 \\
0.8 \\
0.9 \\
1.0\end{array}$ & $\begin{array}{r}10 \\
9 \\
8 \\
7 \\
6 \\
5 \\
4 \\
3 \\
2 \\
1\end{array}$ & $\begin{array}{r}0 \cdot 0 \\
2 \cdot 3 \\
2 \cdot 3 \\
10 \cdot 7 \\
25 \cdot 5 \\
37 \cdot 6 \\
15 \cdot 9 \\
5 \cdot 7 \\
0.0 \\
0.0\end{array}$ & $\begin{array}{r}0-10 \\
11-20 \\
21-30 \\
31-40 \\
41-50 \\
51-60 \\
61-70 \\
71-80 \\
81-105 \\
-\end{array}$ & $\begin{array}{r}24 \cdot 4 \\
21 \cdot 6 \\
14 \cdot 7 \\
11 \cdot 3 \\
10 \cdot 3 \\
5 \cdot 1 \\
2 \cdot 9 \\
1 \cdot 7 \\
7 \cdot 9 \\
-\end{array}$ \\
\hline Total & .. & 99.9 & & $99 \cdot 9$ \\
\hline
\end{tabular}

\begin{tabular}{|c|c|c|c|}
\hline Weltmann reaction & Percentage & Sedimentation rate & Percentage \\
\hline $\begin{array}{l}\text { Enlarged band } \\
\text { Normal band } \\
\text { Slightly narrowed } \\
\text { band. }\end{array}$ & $\begin{array}{r}5 \cdot 7 \\
53 \cdot 4 \\
25 \cdot 5\end{array}$ & $\begin{array}{l}\text { Normal values } \\
\text { Slightly increased .. }\end{array}$ & $\begin{array}{l}24 \cdot 4 \\
24 \cdot 4 \\
36 \cdot 3\end{array}$ \\
\hline $\begin{array}{l}\text { Markedly narrowed } \\
\text { band. }\end{array}$ & $15 \cdot 3$ & Markedly increased & $39 \cdot 2$ \\
\hline Total & 99.9 & & 99.9 \\
\hline
\end{tabular}

\section{Analysis and Comment}

In order to be able to assess the value of the Weltmann reactions in all our cases, we drew up at the beginning a series of questions, the answers to which might give us a real idea of how this test behaves in rheumatoid arthritis. Our observations are not and do not pretend to be definite; we hope to continue them over a larger number of cases and a much longer period of time.

Our questions were:

1. Which, in rheumatoid arthritis, is the more sensitive reaction, the Weltmann test, or the erythrocyte sedimentation rate?

2. How does the Weltmann reaction behave in relation to the particular stage of rheumatoid arthritis?

3. Is the narrowing of the flocculation band in rheumatoid arthritis proportional to that observed in rheumatic fever?

4. Is it possible to give a prognosis, taking as a basis the flocculation band?

5. Is it possible to make such a prognosis in anticipation, even before the sedimentation rate shows any change?

6. Does an enlargement of the flocculation band occur in the terminal stage of rheumatoid arthritis?

7. How does the Weltmann reaction behave in normal subjects?

We believe that in answering these questions we did not neglect the investigation of any point on which criticism might arise. 
1. Which is the more sensitive reaction in rheumatoid arthritis, the Weltmann test or the sedimentation rate?

We proceeded to comparative study of the two tests in both stages of arthritis, i.e. in the active and in the inactive stages. Out of 57 cases in the active stage, we were able to follow up 40 during treatment. The remaining 17 cases were not followed up, the sedimentation rate and the Weltmann test being recorded only at the first examination. The results obtained in both groups were as follows:

(a) 40 cases in the active stage, each with several follow-ups. The sedimentation rate showed an increase in $60.3 \%$, and the flocculation band of the Weltmann reaction a narrowing in $58.4 \%$. We found the sedimentation rate slightly increased in $39.6 \%$, and normal flocculation band in $41.5 \%$.

(b) 17 cases, each with only a single follow-up. Increased sedimentation rate in $76.4 \%$, narrowed flocculation band in $70.6 \%$; slightly increased sedimentation rate in $23.5 \%$, and normal flocculation band in $29.4 \%$.

Out of the total of 57 cases in the active stage of arthritis, the results of the sedimentation rate and of the Weltmann reaction were as follows:

$\begin{array}{llll}\text { Increased sedimentation rate } & . & \ldots & 64 \cdot 2 \% \\ \text { Narrowed flocculation band } \ldots & \ldots & 61 \cdot 4 \% \\ \text { Slightly increased sedimentation rate } & . . & 35 \cdot 7 \% \\ \text { Normal flocculation band } & . & \ldots & 38 \cdot 5 \%\end{array}$

Our observations on the inactive stage were limited to the same 40 cases with several follow-ups - these having passed into the inactive stage as a result of the treatment-and to another 9 cases in which we could not proceed further than a single follow-up. Out of the first group of 40 cases the results were as follows: increased sedimentation rate in $8.5 \%$; narrowed flocculation band in $22.8 \%$; slightly increased sedimentation rate in $91.4 \%$; and normal flocculation band in $77 \cdot 1 \%$. In the second group we observed increased sedimentation rate in $22.2 \%$; narrowed flocculation band in $33.3 \%$; slightly increased sedimentation rate in $77.7 \%$; and normal flocculation band in $66.6 \%$. Considered jointly, the two groups, with a total of 49 cases, furnished the following results in the inactive stage of arthritis:

$\begin{array}{llll}\text { Increased sedimentation rate } & . & \ldots & 11 \cdot 3 \% \\ \text { Narrowed flocculation band } & . & \ldots & 25.0 \% \\ \text { Slightly increased sedimentation rate } & . . & 88.5 \% \\ \text { Normal flocculation band } & . . & . . & 75.0 \%\end{array}$

It is to be noted that during the active stage of arthritis both tests followed a parallel course, the Weltmann test being less sensitive than the sedimentation rate by only $2.8 \%$. We therefore disagree with Kling's results. Kling found, in his 98 cases of rheumatoid arthritis, that the Weltmann reaction in $29 \%$ was less sensitive than the sedimentation rate. According to our observations, both reactions showed the same sensitivity in this stage of arthritis. In the inactive stage, however, there occurred a small discrepancy between the two reactions in the $\mathbf{4 0}$ observed cases, the sedimentation rate showing an increase in $11.3 \%$ and the flocculation band being narrowed in $25 \%$. In this stage of arthritis the Weltmann test showed greater evidence of activity of the disease, even when all signs and symptoms - objective and subjective - had apparently disappeared, and the sedimentation rate was normal. We know that rheumatoid arthritis is a cyclic disease with alternate periods of activity and remission. The value of the Weltmann reaction consists precisely in its demonstration of the activity of the rheumatic process in the clinically inactive stage, when other features suggest that it has been arrested.

2. How does the Weltmann test behave in the active and inactive stages of rheumatoid arthritis?

We have just seen that the Weltmann reaction shows a tendency toward a narrowing of the flocculation band during the active stage of arthritis. It was observed that, among our 57 cases, narrowing of the flocculation band occurred in $61.4 \%$, compared with $64.2 \%$ with increased sedimentation rate. In the resting stage there is a tendency toward normalization of the flocculation band $(75 \%)$, compared with $88.5 \%$ of normal sedimentation rate values. In the 57 cases in the active stage, we observed $38.5 \%$ of the Weltmann reactions with a normal flocculation band, and $35.7 \%$ with normal sedimentation rate, these results being practically alike. These figures are undoubtedly very high, and should not be interpreted as a possible failure of the two reactions, but as indices of a favourable prognosis in the active stage.

3. Is the narrowing of the flocculation band in rheumatoid arthritis proportional to that observed in rheumatic fever?

In the cases of rheumatoid arthritis in the active stage we observed $64.6 \%$ with flocculation in tube 5 , $26.1 \%$ in tube $4,6.1 \%$ in tube 3 , and $3.0 \%$ in tube 2 , i.e. $90.7 \%$ with flocculation restricted to tubes 5 and 4 . In the active stage of rheumatic fever, however, the flocculation band was as a rule much narrower, generally in tubes 1,2 , and 3 -the serum of one of our patients having shown a total absence of flocculation. Thus the degree of narrowing of the flocculation band in rheumatoid arthritis is lower than in the active stage of rheumatic fever.

4. Is it possible to give a prognosis, taking as a basis the flocculation band?

In order to be able to answer this question we need to know the behaviour of the sedimentation rate and of the Weltmann reaction, as well as the degree of activity of the arthritis in certain stages of its progress. For this purpose we observed 40 cases for about six months, dividing the patients into three different groups, as follows:

(a) Cases with increased sedimentation rate and simultaneous normal flocculation band.-We watched the Weltmann reactions and the sedimentation rate, as well as the general and articular conditions, in 21 cases. We concluded that, in patients who showed a flocculation band within normal limits, 
the tendency was towards a remission of the arthritis - a fact which has been confirmed by general and biological examinations, even in spite of the sedimentation rate being high.

In order to allow of a right valuation of the sensitiveness of the Weltmann reaction, we will describe what happened in a few cases. In a patient whose sedimentation rate was at first raised, but who had a normal flocculation band, the symptoms totally disappeared. But in the last checked control, in spite of the normal value of the sedimentation rate - which rose to 5 and $16 \mathrm{~mm}$. respectively at the end of the first and second hours - the flocculation band was narrowed in tube 5 , coinciding with a slight aggravation of the articular picture. In another case we were able to observe how the readings of the Weltmann reaction anticipated those of the sedimentation rate. When we proceeded to check one of the periodical controls, we observed that the patient was in complete resting condition, with sedimentation value of 19 and $42 \mathrm{~mm}$., while the Weltmann reaction showed flocculation in tube 5 (narrowed band). Thirty days later this patient showed a worsening of the general and joint conditions, the sedimentation rate rising to 22 and $55 \mathrm{~mm}$. in the first and second hours. In this case the Weltmann reaction gave signs a month before the sedimentation rate of a deteriorating prognosis. A third patient showed an arthritis in a fully active stage, the sedimentation rate rising to 58 and $94 \mathrm{~mm}$. The Weltmann reaction, however, showed flocculation up to tube 7 1/2 (slightly enlarged band), thus enabling us to give a good prognosis in spite of the precarious general and articular conditions and the increased sedimentation rate. In fact, three months later the sedimentation values fell to 30 and $60 \mathrm{~mm}$., the Weltmann reaction still showing a slightly enlarged band. Both the general and articular conditions had improved considerably, the patient being discharged as she was considered able to resume her ordinary activities. This is a significant example of the great sensitivity of the Weltmann reaction, which enabled us to establish a favourable prognosis early-which apparently could not have been done in any other way.

(b) Cases with normal sedimentation rate and flocculation band.-Out of the 40 cases, only 8 showed exacerbation, the Weltmann reaction and the sedimentation rate keeping within normal limits. All the cases proceeded toward complete regression of the articular picture. Only one patient who showed normal reactions at the periodical examinations complained at last of slight joint pains and of marked Schönlein-Henoch purpura. On that occasion the sedimentation rate was within its normal limits, with 9 and $24 \mathrm{~mm}$., but the Weltmann reaction showed flocculation in tube 5 (narrowed band).

(c) Cases with increased sedimentation rate and narrowed flocculation band.-In the 6 cases of this group the general and articular conditions became greatly aggravated.
Having completed the analysis of these 40 cases, we may say that a normal or enlarged flocculation band means a favourable prognosis even when the sedimentation rate is increased-the contrary happening in cases with a narrowed flocculation band. The sedimentation rate and the Weltmann reaction are two subsidiary laboratory tests which ought always to be analysed jointly in order to obtain exact information on the true clinical picture of arthritis, and on its future evolution. In order to assess the flocculation band as an index of a bad prognosis, several examinations, checked at regular intervals and showing the constant narrowing of the band, are necessary.

5. Is it possible to make a prognosis in anticipation, before there is any change in the sedimentation rate?

In a few cases, and precisely in those showing marked general and articular involvement with increased sedimentation rate, and in which, therefore, a cautious prognosis was imperative, the signs in the Weltmann reaction preceded by several months those in the sedimentation rate, and this fact helped us in reaching a prognosis. For example, a patient showed on July 15, 1944, marked articular involvement with a much increased sedimentation ratethat is, $125 \mathrm{~mm}$. and $131 \mathrm{~mm}$. respectively at the end of the first and second hours. The Weltmann reaction, however, was within its normal limits, with a flocculation band up to tube 6 . Further examinations enabled us to observe a gradual return to normal of the general and articular picture as well as of the sedimentation rate, while the Weltmann continued in tube 6 . Four months later, on Nov. 20 of the same year, the articular condition and the sedimentation rate appeared normal, the sedimentation rate having fallen to $1 \mathrm{~mm}$. and $6 \mathrm{~mm}$. at the end of the first and second hours.

A case similar to the one mentioned above showed a poor general and articular picture, with sedimentation rate at $58 \mathrm{~mm}$. and $94 \mathrm{~mm}$., but with a flocculation band slightly enlarged (tube $71 / 2$ ). Three months later, after treatment had begun, the sedimentation rate fell to 30 and $60 \mathrm{~mm}$., the general and articular conditions returning to normal. A third patient, with a marked joint involvement, showed a slightly increased sedimentation rate, with $19 \mathrm{~mm}$. and $42 \mathrm{~mm}$., but the Weltmann test reacted up to tube 5. Three and a half months later no alterations were observed. The sedimentation rate rose to $25 \mathrm{~mm}$. and $46 \mathrm{~mm}$., and the prognosis was confirmed.

These examples show how a reading of the Weltmann reaction may establish a favourable or a reserved prognosis many months ahead of the sedimentation rate.

6. Is there an enlargement of the flocculation band in the terminal stage of rheumatoid arthritis?

It seems that in the terminal stage of rheumatoid arthritis the flocculation band tends to enlarge. We were unable to reach any definite conclusion in 
this matter because the number of observed cases in this stage of arthritis was small. For this reason we shall continue our investigations.

7. How does the Weltmann reaction behave in normal subjects?

In normal subjects both the Weltmann reaction and the sedimentation rate show a tendency toward normal. However, among 15 apparently normal individuals we observed in 4 of them $(26.6 \%)$ a narrowed flocculation band up to tube 5 , in spite of the sedimentation rate being normal. In 2 other cases we observed the presence of an increased sedimentation rate with normal flocculation band. The explanation of this may be that in such control subjects there might have been concomitant processes responsible for these alterations-a fact which we did not attempt to investigate.

We are inclined from the analysis and interpretation of our cases to accept the sensitivity of the Weltmann reaction, which has frequently been of great help. We are, however, unable to reach positive conclusions, because our investigations are not definite, and we need to observe a larger number of cases and verify the sequence of events during a longer period of time. However, from the analysis of the results obtained, we have the impression that Weltmann's serum-coagulation test is very useful, not only because it facilitates early diagnosis, but also because it enables us to form an opinion as to probable progress in any given case, and as to the final therapeutic results.

\section{Summary}

In the observation of 200 Weltmann coagulation reactions in 85 cases-66 of which (180 reactions) had rheumatoid arthritis in various stages-the results were as follows:

1. The sensitivity of the Weltmann reaction was practically the same as that of the sedimentation rate, the Weltmann reaction being only $2 \cdot 8 \%$ below the sedimentation rate.

2. During the active stage of rheumatoid arthritis the Weltmann reaction showed a narrowed flocculation band; during the resting periods the band was normal.

3. In rheumatoid arthritis the narrowing of the flocculation band was not so marked as in rheumatic fever. It occurred only up to tube 4 .

4. In rheumatoid arthritis it is possible to base the prognosis on the flocculation band. The prognosis was favourable in cases which showed a normal or enlarged band, and it was unfavourable in cases with a narrowed band.

5. When based on the Weltmann reaction, a favourable or reserved prognosis may, in certain cases, be advanced several months earlier than when the sedimentation rate is taken as a guide.

6. In the terminal stage of rheumatoid arthritis there is a tendency towards an enlargement of the flocculation band.

7. In apparently normal subjects the flocculation band appeared normal in most cases.

\section{REFERENCES}

Bonilla, W. A., and Lagrotta, E. (1943). Anal. Asoc. Quim. Farm. del Uruguay, 1, 19.

Kling, D. H. (1941). Annals of the Rheumatic Diseases, 2, 256.

Milles, H. L., and Salt, H. B. (1941). Ibid., 2, 192.

Weltmann, O. (1930). Med. Klin., 26, 240. 